\title{
Managing child and adolescent mental health problems in primary care: taking the leap from knowledge to practice
}

\author{
Aaron K. Vallance ${ }^{1,2}$, Tami Kramer ${ }^{1,3}$, Dick Churchill ${ }^{4}$ and M. Elena Garralda ${ }^{1,3}$ \\ ${ }^{1}$ Clinical Research Fellow, Academic Unit of Child and Adolescent Psychiatry, St Mary's Campus, Imperial College \\ School of Medicine (Imperial College London), Norfolk Place, London, UK \\ ${ }^{2}$ Consultant Child and Adolescent Psychiatrist, Surrey and Borders Partnership Foundation Trust, Surrey, UK \\ ${ }^{3}$ Consultant Child and Adolescent Psychiatrist, Central and North West London Foundation Trust, London, UK \\ ${ }^{4}$ Associate Clinical Professor, Division of Primary Care, Queen's Medical Centre, University of Nottingham, \\ Nottingham, NG7 2RD, UK
}

\begin{abstract}
In 2009, a conference at Imperial College London brought together experts on the primary care provision of child and adolescent mental health. The following paper highlights various themes from the conference, and particularly focuses on general practice. Despite international and national guidance, child and adolescent mental health provision in primary care is limited in the UK and globally. We argue that primary care services are in fact well placed to assess, diagnose, and manage child and adolescent mental health problems. The barriers to such provision are considered from the perspective of both service users and providers, and the possible ways to overcome such challenges are discussed. The paper is informed by various epidemiological and intervention studies and comparisons between different countries and health systems are explored.
\end{abstract}

Key words: child mental health; general practice; healthcare management; intervention; prevention; treatment

Received 29 June 2010; accepted 3 July 2011; first published online 22 August 2011

\section{Introduction}

The World Health Organization has identified that primary care is in critical need of investment to tackle the suffering and impairment that young people face from mental disorder (World Health Organization, 2005). However, the quality and type of provision remain diverse across different countries. Worldwide, various types of professionals (general practitioners (GPs), paediatricians, nurses, health visitors, and psychologists) operate in numerous settings (primary care clinics, child health clinics, school medical services, emergency

Correspondence to: Dr Aaron K. Vallance, Academic Unit of Child and Adolescent Psychiatry, Imperial College School of Medicine, St Mary's Campus, Norfolk Place, London W2 1PG, UK. Email: a.vallance@imperial.ac.uk

(C) Cambridge University Press 2011 departments, and ambulatory outpatient departments) within different types of systems. Even within Europe, countries range considerably in their organisation of primary paediatric care (Katz et al., 2002).

Despite these differences, all countries share the same problem of lack of capacity and skilled personnel. A number of national policy initiatives have addressed this directly (Health Advisory Service, 1995; US Public Health Service, 2000; Australian Health Ministers, 2003), although most countries, both developed and developing, still lack any specific child and adolescent mental health policy (Shatkin et al., 2004).

In the United Kingdom, the National Service Framework, National Institute for Health and Clinical Excellence (NICE), and the National CAMHS (Child and Adolescent Health Service) 
Review identify primary care (which in the United Kingdom is predominantly general practice) as a key setting to address child and adolescent mental health problems. Arguably, this does not often translate into practice.

In 2009, a conference at Imperial College London brought together experts on the primary care provision of child and adolescent mental health. This paper presents key themes from the conference, with a particular emphasis on general practice. Themes included the barriers to child and adolescent mental health provision in primary care from the perspective of both service users and providers, and ways in which these challenges may be addressed. This paper also cites the relevant literature from the writings of conference attendees, as well as literature discussed at the meeting itself.

\section{Service-user attitudes towards primary care services}

With stigma and poor accessibility often cited as arguments against specialist mental health services, and with concerns over the confidentiality of visiting school-based counsellors, primary health care in the form of general practice should be well placed for young people in need of help for mental health problems. However, although families and young people will be familiar with their local general practice as a source of help for physical problems, many do not realise that they can turn to them for support for emotional difficulties; others do not believe that such professionals are adequately trained to deal with such problems (Biddle et al., 2006). Even when young people do recognise general practice as a potential source of help, many are reluctant to discuss their emotional difficulties, particularly if there are concerns about the confidentiality of the consultation (Churchill et al., 2000; Martinez et al., 2006). Meanwhile, parents often do not express their concerns to GPs (Ellingson et al., 2004; Sayal and Taylor, 2004). Nevertheless, young people can be clearly appreciative when appropriate interventions are offered in general practice (Gledhill et al., 2003).

What makes a young person with depression decide to see their GP? Ferrin et al.'s (2009) case-control study looked at adolescents with high levels of depressive symptoms, and compared those attending general practice with those not attending. Attendance was associated with lower socio-economic status, non-White ethnicity, non-intact families, and not believing that doctors are only interested in physical symptoms. Furthermore, logistic regression analysis showed gender differences: attendance in males was associated with more physical and less marked depressive symptoms, in females by non-White ethnicity and not believing that doctors are only interested in physical symptoms. The study shows that - over and above demographic and clinical features a young person's expectation of the attitude of the practitioner may influence whether they seek help through their GP for mental health problems, particularly for females. Research in paediatric primary care also shows that adolescents particularly value practitioners' communication and interpersonal skills, as well as their respect (Byczkowski et al., 2010).

With regard to younger children, help-seeking primarily originates from parents. Sayal et al. (2010) used focus groups to explore which factors influence parental help-seeking for children with mental health problems. Echoing the research above, a trusting relationship in the GP who can validate parental concerns, show an interest in the child and family, and offer continuity of care, were cited as key factors to facilitate helpseeking. Barriers, however, included: embarrassment, stigma, and concerns about being labelled, for example, as a 'poor parent' or the child receiving a diagnosis. Parents also felt that short appointments did not offer sufficient time to address their child's problems.

\section{Practitioner attitudes towards children and mental health}

Young people are not the only ones reluctant to discuss their emotional difficulties. Primary care clinicians themselves frequently avoid exploring such issues with them, despite this being a critical factor in detecting psychological problems (Martinez et al., 2006). General practitioners vary in their construction of mental health problems: many remain sceptical about the diagnostic validity of psychiatric disorders; a number of them believe that conditions such as hyperkinetic disorder 
are over-diagnosed; others report lack of confidence in diagnosis (Klasen and Goodman, 2000) and management (Churchill, 2008); many are concerned about 'over-medicalising' normal distress (Iliffe et al., 2004) and stigmatisation (Churchill et al., 2000; Churchill, 2008), or advocate that responsibility lies in other agencies such as schools, community organisations, and specialist services.

Such concerns are understandable, but they do not reflect current medical knowledge or health service policy. This makes it imperative for primary care staff to be appropriately trained in recognising, understanding, and managing common psychiatric disorders in young people. There are strong arguments for primary care to have a role in addressing child and adolescent mental health problems, particularly as physical symptoms, psychosocial problems, and psychiatric disorder often occur together in the children and adolescents who are consulting them. As such, primary care is ideally placed to contribute to mental health promotion, prevention, and early intervention. This is particularly enhanced by the GP's often intimate and long-standing knowledge of the family.

\section{Identifying child mental health problems in primary care}

What do we already know about the identification of child mental health problems in primary care? In the first place, it is well established that young people generally have regular contact with primary health-care services. Within the United Kingdom, over $90 \%$ of pre-school children and two-thirds of 5-14-year-olds will consult primary care, and half of 13-17-year-olds will consult their GPs, at least once a year (OPCS, 1995; Kramer et al., 1997). In the United States, over $70 \%$ of adolescents see a physician at least once a year (Frankenfield et al., 2000).

Moreover, epidemiological research shows that mental health problems, with accompanying suffering, impairment, and continuity, are common in childhood and adolescence. Such difficulties often remain hidden during consultations: whereas only $2-10 \%$ of child and adolescent primary care consultations are explicitly for emotional or behavioural complaints, $10-25 \%$ of younger children and $40 \%$ of adolescents who attend primary care have an underlying psychiatric disorder (Garralda and Bailey, 1986; Costello et al., 1988; Gureje et al., 1994; Kramer and Garralda, 1998).

The key is to look beyond the description of physical symptoms. Young people may present with physical disorders, but contributing psychological factors (eg, stress-exacerbating asthma) have been identified in a fifth of schoolchildren attending primary care and half in paediatric clinics (Garralda and Bailey, 1990). Furthermore, young people commonly present with recurrent unexplained functional physical symptoms, a somatised expression of stress often accompanied by psychiatric disorder. One study identified a comorbid anxiety disorder in over three-quarters of 8-15-year-olds attending primary care with recurrent abdominal pain, and $43 \%$ had a depressive disorder (Campo et al., 2004). Nevertheless, rates of recognition of psychiatric disorder in young people attending primary care are poor (Garralda and Bailey, 1986; Chang et al., 1988; Kramer and Garralda, 1998; Sayal and Taylor, 2004). Studies in the United States and Australia show that many young people have contact with primary care in the month before suicide or self-harm (Pfaff et al., 2001; Luoma et al., 2002); however, fewer than half of primary care physicians report screening their adolescent patients for suicide risk (Frankenfield et al., 2000).

What then influences the recognition of child and adolescent mental health disorder in primary care? Studies show that recognition is associated with severity of the problem, explicit expression of concerns by parents during consultations, as well as with social factors such as age (more in middle childhood), male gender, receiving benefits, and broken homes; it is also linked to clinician-patient alliance (Goldberg et al., 1984; Horwitz et al., 1992; Kramer and Garralda, 1998; Sayal and Taylor, 2004; Martinez, et al., 2006). All of these factors make it likely for young people to reach thresholds for referral to specialist care by primary health services.

The challenge - in addition to ensuring wide recognition and referral of severe problems is in increasing recognition of less severe and overt problems that may respond to a primary care intervention. Training professionals may improve overall recognition rates, as might screening questionnaires (Luby et al., 2004), such as the Strengths and Difficulties Questionnaire. 
Questionnaires, however, might also over-identify the number of children and adolescents requiring further assessment, and thereby risk further burdening limited resources. In addition, some GPs have expressed some scepticism over the utility of questionnaires, such as those used in the Quality and Outcomes Framework (QOF) for depression (Dowrick et al., 2009). Questionnaires are perhaps best used to guide further psychological and psychosocial routes of enquiry.

\section{Preventing and treating child mental health problems in primary care}

Improving the identification of child and adolescent psychiatric disorder raises the question as to who then intervenes. A study in the United States showed that even when mood or anxiety disorders were identified in primary care, young patients were not particularly likely to receive counselling in this setting, but instead tended to be referred to specialised services (Wren et al., 2005).

Yet, primary care is well placed for managing child and adolescent psychiatric disorders. Interventions such as psycho-education, brief cognitive/ behaviour therapy, medication management, and parenting support are effective and can be feasibly delivered. Such treatments may also be enhanced when there are long-standing therapeutic relationships with the primary care clinicians.

The majority of research into child and adolescent psychiatric intervention occurs in specialised settings, but a notable exception is a randomized study on adolescents with depression carried out in the United States by Asarnow et al. (2005). Compared with usual care, a 'quality improvement intervention' (which included expert leader teams with care managers supporting a range of interventions, that is, cognitive behavioural therapy (CBT), medication, combined CBT with medication, care manager follow-up, or specialist referral) resulted in significantly fewer depressive symptoms, higher quality of life, and greater satisfaction with mental health care after six months, although almost a third of young people continued to show severe depressive symptoms.

Primary care could also play an important role in preventative mental health care. After all, the primary care team already delivers public health programmes targeting relevant risk and resilience factors, such as family planning programmes, prenatal care, promotion of nutrition, and child safety information. There is empirical evidence supporting the implementation of parent training programmes (Webster-Stratton et al., 1989; Olds et al., 1998; Scott et al., 2001), and an Australian study of preventative GP consultations during a child's first four years showed favourable outcomes 6 and 20 years later (Cullen and Cullen, 1996). Dissemination of information on child health, development, behaviour, and positive parenting programmes could realistically be achieved in primary care, particularly through teamwork with professionals such as nurses and health visitors. The UK government's 'No Health Without Mental Health' pledges to increase the health visitor workforce to offer all families support when they become parents, and aims to ensure that health visitors and school nurses are equipped to identify and help parents and young people who need support with their emotional or mental health (Department of Health, 2011).

Any such intervention relies of course upon people actually attending primary care for their mental health problems; as discussed above, this may not always be the case. Public education efforts may therefore help young people and parents identify mental health problems in the community and direct them to primary care for advice.

\section{Training primary care practitioners}

To improve identification and management of child and adolescent mental health problems, primary care professionals need to be adequately trained. A range of such initiatives have been successfully carried out (Bernard et al., 1999; Gledhill et al., 2003) but are generally scarce (Levav et al., 2004). The following programmes were presented to the conference:

In London, the Therapeutic Intervention in Depressed Youths programme has trained GPs to screen and identify depressive disorder, and provide initial management within a 10-minute appointment. Management of mild to moderate depressive disorder includes psycho-education, promotion of self-help, and advice about coping strategies; information is given both verbally and in leaflets. Preliminary research shows feasibility (Gledhill et al., 2003), user-acceptability,

Primary Health Care Research \& Development 2011; 12: 301-309 
and increased detection rates while a randomized trial is being planned.

The Adolescent Health E-learning project developed by a collaboration including the Royal College of Paediatrics and Child Health, E-Learning for Healthcare, and the Department of Health, includes a module on adolescent mental health (Department of Health). Each of the seven selfdirected 20-minute sessions includes learning objectives, visual images, interactive material, and self-assessment. E-training can be freely operated 'anytime, anyplace, and at any pace'; material can be easily updated and used in parallel with other learning. The programme has yet to undergo thorough peer-evaluation and accreditation.

In South Australia, the Headstart programme arose in response to government incentives for GPs to train in mental health. The programme helps GPs construct patient stories and genograms, assess patients' normal feelings, and review functioning. The 6-hour training session is facilitated by an educator and attended by local CAMHS clinicians to promote local links. Following training, regular E-bulletins help consolidate learning and GP graduates have telephone access to consult specialist staff on clinical cases.

In the North-East of England, a toolkit has been prepared by the Charlie Waller Memorial Trust and the Mental Health Foundation to assist primary health-care professionals in the recognition and management of psychological problems (Mental Health Foundation). This consists of specific tools to help identify problems and to advise on problemsolving skills and mental health promotion.

\section{The interface between primary care and specialist child mental health services}

Even in countries with well-developed specialist child and adolescent mental health services, limited resources mean that only a small proportion of young people with psychiatric disorder currently receive help (Rushton et al., 2002). Specialist services are often working to capacity with long waiting lists for treatment (US Public Health Service, 2000). In the United Kingdom, GP referrals consistently make up a large proportion of all referrals made to CAMHS services. As already mentioned, referral rates correlate with disorder severity, male gender, antisocial symptoms, relationship problems, psychosocial disadvantage, and parental request (Garralda and Bailey, 1988; Bailey and Garralda, 1989; BriggsGowan et al., 2000; Sayal et al., 2002).

The relationship between primary care and specialist service need not be just one of transferral of care. Various models of primary and specialist care interface have been proposed, and need not involve exclusive care from one or the other. For chronic problems such as Attention Deficit Hyperactivity Disorder, a comprehensive model of care could include long-term monitoring within primary care with intermittent involvement of specialist services for medication review or adjuvant behaviour therapy.

The 'Shifted out-patient' model, meanwhile, sees specialist services operating within primary care. As identified in Bower et al.'s (2001) systematic review, interventions tend to be brief (6-12 sessions) and include psycho-education, cognitive behaviour therapy, family therapy, counselling, group work, psychodynamic therapy, and psychiatric evaluation and guidance. Unfortunately, studies identified tended to be poor in quality. Comprehensive coverage of this model would also require marked expansion of specialist services and is unlikely to be cost effective.

A less expensive approach may be the 'Consultation liaison' model, where specialist services support primary care professionals by providing ongoing training. Bower et al. (2001) only identified one study on consultation (Neira-Munoz and Ward, 1998), and although Connor et al., (2006) describe a similar model, neither includes data on patient outcomes. A survey of CAMHS services in England demonstrated that a dedicated liaison service enhanced such collaborative work with primary care (Bradley et al., 2003).

The United Kingdom has developed the Primary Mental Health Worker role to work with both primary and specialist child and adolescent mental health services, and to bridge the gap between the two (Macdonald et al., 2004). PHMWs are usually nurses, but sometimes social workers or psychologists. Although available to take cases, their main function is consultation liaison and to support recognition of disorders and referral to specialist services (Department of Health, 2004). A similar model has been developed in a service in South Africa (Pillay and Lockhat, 1997) and in the United States 
(Campo et al., 2005) where primary care clinicians refer young people to Advanced Practice Nurses for further evaluation; patients are then either transferred to specialist care or more frequently returned to the primary care clinician. There is now a need for a systematic study of patient outcomes.

\section{Future developments}

Countries may vary in their primary care systems, but they experience similar challenges when it comes to child mental health provision (Veit et al., 1995; Jacobson et al., 2002). Difficulties include financial and time constraints, and the lack of practitioner training and confidence in detecting and managing disorders. Such challenges are exacerbated by a global lack of child and adolescent mental health policy (Shatkin et al., 2004).

A sound policy base is critical for future investment in and expansion of the respective programmes of research, professional training, and national guideline development, in conjunction with service delivery based on locally determined, culturally sensitive needs assessment (Rahman et al., 2000). These programmes are mutually dependent. Research should focus on pragmatic evaluations of primary care, such as on disorder-specific management techniques, the interface between primary and specialist care, and the utility of training programmes. Evidence should then be used to influence attitudes and to inform guidelines and national standards. The attitudes of professionals and service users will influence quality standards to inform commissioning priorities. Within the United Kingdom, a specific QOF would help to prioritise child and adolescent mental health provision in general practice. Political investment brings research investment, thereby continuing the cycle.

Service quality standards and indicators for child and adolescent mental health in primary care are currently being developed by a research study led by Kapil Sayal, which was presented at the conference. The study ascertained perspectives from both parents and a range of other stakeholders, via a series of focus groups and Delphi consultation. Having such quality standards would not only help describe quality of mental health care, but also inform commissioning priorities and influence the interface between primary care and CAMHS.

In practice, multifaceted programmes that integrate improvements in detection, treatment and follow-up, and include combinations of clinician and patient education, nurse case management, enhanced support from specialist services and monitoring of medication, are likely to be most effective (Gilbody et al., 2003; WHO Regional Office for Europe's Health Evidence Network, 2004). Policy developments could also encompass other agencies involved with young people, including pre-school, education, welfare, and juvenile justice, as has already been demonstrated in the United Kingdom and the United States (Health Advisory Service, 1995; US Public Health Service, 2000).

History has unfortunately not seen political and financial investment in child mental health in primary care despite decades of rhetoric supporting this. Nevertheless, the political tide in the United Kingdom may be changing: Lord Darzi's legacy of health-care reforms includes an increased political focus on primary care and early intervention work; the Department of Health's recent 'No Health Without Mental Health' initiative highlights the importance of early intervention with young people, and GP consortia are well placed to understand the broad range of mental health problems experienced by people in the locality (Department of Health, 2011); the former chairman of the Healthcare Commission has identified adolescent mental health as a priority (Kennedy, 2010), and both previous and current prime ministers have advocated the prioritisation of children and adolescents in policy development. Although the current economic downturn will inhibit public sector spending in the near-to-mid future, policymakers should consider that preventing and treating child mental health problems may lead to economic savings later down the line.

\section{Acknowledgements}

The authors thank everyone who attended and contributed to make the conference such a success. Speakers included Dr Maryanne Freer, Dr Julia Gledhill, Dr Kevin Harvey, Professor Steve Iliffe, Dr Jon Jureidini, and Dr Kapil Sayal. They are 
grateful to Claire Murdoch, Chief Executive of Central \& North West London Foundation NHS Trust, for her contribution. The authors have no conflict of interest to declare.

\section{References}

Asarnow, J.R., Jaycox, L.H., Duan, N., LaBorde, A.P., Rea, M.M., Tang, L. and Wells, K.B. 2005: Depression and role impairment among adolescents in primary care clinics. The Journal of Adolescent Health 37, 477-83.

Australian Health Ministers. 2003: National Mental Health Plan 2003-2008. Canberra: Australian Government.

Bailey, D. and Garralda, M.E. 1989: Referral to child psychiatry: parent and doctor motives and expectations. Journal of Child Psychology and Psychiatry 30, 449-58.

Bernard, P., Garralda, E., Hughes, T. and Tylee, A. 1999: Evaluation of a teaching package in adolescent psychiatry for general practitioners. Education for General Practice 10, 21-28.

Biddle, L., Donovan, J.L., Gunnell, D. and Sharp, D. 2006: Young adults' perceptions of GPs as a help source for mental distress: a qualitative study. The British Journal of General Practice 56, 924-31.

Bower, P., Garralda, E., Kramer, T., Harrington, R. and Sibbald, B. 2001: "The treatment of child and adolescent mental health problems in primary care: a systematic review". Family Practice 18, 373-82.

Bradley, S., Kramer, T., Garralda, E., Bower, P., MacDonald, W., Sibbald, B. and Harrington, R. 2003: Child and adolescent mental health interface work with primary services: a survey of NHS provider trusts. Child and Adolescent Mental Health $8,170-76$.

Briggs-Gowan, M.J., Horwitz, S.M., Schwab-Stone, M.E., Leventhal, J.M. and Leaf, P.J. 2000: Mental health in pediatric settings: distribution of disorders and factors related to service use. The Journal of American Academy of Child Psychiatry 39, 841-49.

Byczkowski, T.L., Kollar, L.M. and Britto, M.T. 2010: Family experiences with outpatient care: do adolescents and parents have the same perceptions? Journal of Adolescent Health 47, 92-98.

Campo, J.V., Bridge, J., Ehmann, M., Altman, S., Lucas, A., Birmaher, B., Di Lorenzo, C., Iyengar, S. and Brent, D.A. 2004: Recurrent abdominal pain, anxiety, and depression in primary care. Pediatrics 113, 817-24.

Campo, J.V., Shafer, S., Strohm, J., Lucas, A., Cassesse, C.G., Shaeffer, D. and Altman, H. 2005: Pediatric behavioral health in primary care: a collaborative approach. Journal of the American Psychiatric Nurses Association 11, 276-82.

Chang, G., Warner, V. and Weissman, M.M. 1988: Physicians' recognition of psychiatric disorders in children and adolescents. American Journal of Disease of Children 142, 736-39.
Churchill, R.D. 2008: Child and adolescent mental health. In Cohen, A., editor, Delivering mental health for primary care: an evidence-based approach. London, UK: RCGP, 157-84.

Churchill, R.D., Allen, J., Denman, S., Williams, D., Fielding, K. and von Fragstein, M. 2000: Do the attitudes and beliefs of young teenagers towards general practice influence actual consultation behaviour? The British Journal of General Practice 50, 953-57.

Connor, D.F., McLaughlin, T.J., Jeffers-Terry, M., O'Brien, W.H., Stille, C.J., Young, L.M. and Antonelli, R.C. 2006: Targeted child psychiatric services: A new model of pediatric primary clinician-child psychiatry collaborative care. Clinical Pediatrics 45, 423-34.

Costello, E.J., Costello, A.J., Edelbrock, C., Burns, B.J., Dulcan, M.K., Brent, D. and Janiszewski, S. 1988: Psychiatric disorders in pediatric primary care. Prevalence and risk factors. Archives of General Psychiatry 45, 1107-16.

Cullen, K.J. and Cullen, A.M. 1996: Long-term follow-up of the Busselton six-year controlled trial of prevention of children's behavior disorders. The Journal of Pediatrics 129, 136-39.

Department of Health. 2004: National service framework for children, young people and maternity services: the mental health and psychological well-being of children and young people. London: Department of Health.

Department of Health. Adolescent health E-learning project. Retrieved from www.e-lfh.org.uk

Department of Health. 2011: No health without mental health; a cross-government mental health outcomes strategy for people of all ages. Retrieved June 2011 from http://www.dh. gov.uk/prod_consum_dh/groups/dh_digitalassets/documents/ digitalasset/dh_124058.pdf

Dowrick, C., Leydon, G.M., McBride, A., Howe, A., Burgess, H., Clarke, P., Maisey, S. and Kendrick, T. 2009: Patients' and doctors' views on depression severity questionnaires incentivised in UK quality and outcomes framework: qualitative study. The British Medical Journal 338, 762.

Ellingson, K.D., Briggs-Gowan, M.J., Carter, A.S. and Horwitz, S.M. 2004: Parent identification of early emerging child behavior problems: predictors of sharing parental concern with health providers. Archives of Pediatric \& Adolescent Medicine 158, 766-72.

Ferrin, M., Gledhill, J., Kramer, T. and Garralda, M.E. 2009: Factors influencing primary care attendance in adolescents with high levels of depressive symptoms. Social Psychiatry and Psychiatric Epidemiology 44, 825-33.

Frankenfield, D.L., Keyl, P.M., Gielen, A., Wissow, L.S., Werthamer, L. and Baker, S.P. 2000: Adolescent patients healthy or hurting?: missed opportunities to screen for suicide risk in the primary care setting. Archives of Pediatric \& Adolescent Medicine 154, 162-68.

Garralda, M.E. and Bailey, D. 1986: Children with psychiatric disorders in primary care. Journal of Child Psychology and Psychiatry 27, 611-24. 
Garralda, M.E. and Bailey, D. 1988: Child and family factors associated with referral to child psychiatrists. British Journal of Psychiatry 153, 81-89.

Garralda, M.E. and Bailey, D. 1990: Paediatrician identification of psychological factors associated with general paediatric consultations. Journal of Psychosomatic Research 34, 303-12.

Gilbody, S., Whitty, P., Grimshaw, J. and Thomas, R. 2003: Educational and organizational interventions to improve the management of depression in primary care: a systematic review. The Journal of the American Medical Association 289, 3145-51.

Gledhill, J., Kramer, T., Iliffe, S. and Garralda, M.E. 2003: Training general practitioners in the identification and management of adolescent depression within the consultation: a feasibility study. Journal of Adolescence 26, 245-50.

Goldberg, I.D., Roghmann, K.J., McInerny, T.K., Pless, I.B. and Roghmann, K.J. 1984: Mental health problems among children seen in pediatric practice: prevalence and management. Pediatrics 73, 278-93.

Gureje, O., Omigbodun, O.O., Gater, R., Acha, R.A., Ikuesan, B.A. and Morris, J. 1994: Psychiatric disorders in a paediatric primary care clinic. The British Journal Psychiatry 165, 527-30.

Health Advisory Service. 1995: Child and adolescent mental health services: together we stand. London: HMSO.

Horwitz, S.M., Leaf, P.J., Leventhal, J.M., Forsyth, B. and Speechley, K.N. 1992: Identification and management of psychosocial and developmental problems in communitybased, primary care pediatric practices. Pediatrics 89, 480-85.

Iliffe, S., Gledhill, J., daCunha, F., Kramer, T. and Garralda, M.E. 2004: The recognition of adolescent depression in general practice: issues in the acquisition of new skills. Primary Care Psychiatry 9, 51-56.

Jacobson, L., Churchill, R., Donovan, C., Garralda, E. and Fay, J. 2002: Tackling teenage turmoil: primary care recognition and management of mental ill health during adolescence. Family Practice 19, 401-09.

Katz, M., Rubino, A., Collier, J., Rosen, J. and Ehrich, J.H. 2002: Demography of pediatric primary care in Europe: delivery of care and training. Pediatrics 109, 788-96.

Kennedy, I. 2010: Getting it right for children and young people: overcoming cultural barriers in the NHS so as to meet their needs. Retrieved February 2011 from www.dh.gov.uk/en/Publicationsandstatistics/Publications/ PublicationsPolicyAndGuidance/dh_119445

Klasen, H. and Goodman, R. 2000: Parents and GPs at crosspurposes over hyperactivity: a qualitative study of possible barriers to treatment. The British Journal of General Practice 50, 199-202.

Kramer, T. and Garralda, M.E. 1998: Psychiatric disorders in adolescents in primary care. The British Journal of Psychiatry 173, 508-13.

Kramer, T., Iliffe, S., Murray, E. and Waterman, S. 1997: Which adolescents attend the GP? The British Journal of General Practice 47, 327.

Primary Health Care Research \& Development 2011; 12: 301-309
Levav, I., Jacobsson, L., Tsiantis, J., Kolaitis, G. and Ponizovsky, A. 2004: Psychiatric services and training for children and adolescents in Europe: results of a country survey. European Child \&Adolescent Psychiatry 13, 395-401.

Luby, J.L., Heffelfinger, A., Koenig-McNaught, A.L., Brown, K. and Spitznagel, E. 2004: The Preschool Feelings Checklist: a brief and sensitive screening measure for depression in young children. Journal of the American Academy of Child Psychiatry 43, 708-17.

Luoma, J.B., Martin, C.E. and Pearson, J.L. 2002: Contact with mental health and primary care providers before suicide: a review of the evidence. The American Journal of Psychiatry 159, 909-16.

Macdonald, W., Bradley, S., Bower, P., Kramer, T., Sibbald, B., Garralda, E. and Harrington, R. 2004: Primary mental health workers in child and adolescent mental health services. Journal of Advanced Nursing 46, 78-87.

Martinez, R., Reynolds, S. and Howe, A. 2006: Factors that influence the detection of psychological problems in adolescents attending general practices. The British Journal of General Practice 56, 594-99.

Mental Health Foundation. 2009: Young people with mental health problems. A toolkit for school nurses, primary care and community professionals. Retrieved December 2009 from: www.mhf.org.uk/EasySiteWeb/getresource.axd? AssetID $=73243$

Neira-Munoz, E. and Ward, D. 1998: Child mental health services. Side by side. Health Service Journal 108, 26-27.

Olds, D.L., Henderson, C.R., Cole, R., Eckenrode, J., Kitzman, H., Luckey, D., Petitt, L., Sidora, K., Morris, P. and Powers, J. 1998: Long-term effects of nurse home visitation on children's criminal and antisocial behavior: 15-year follow-up of a randomized trial. The Journal of the American Medical Association 280, 1238-244.

OPCS 1995: Morbidity statistics from general practice. London: HMSO.

Pfaff, J.J., Acres, J.G. and McKelvey, R.S. 2001: Training general practitioners to recognise and respond to psychological distress and suicidal ideation in young people. The Medical Journal of Australia 174, 222-26.

Pillay, A.L. and Lockhat, M.R. 1997: Developing community mental health services for children in South Africa. Social Science \& Medicine 45, 1493-501.

Rahman, A., Mubbashar, M., Harrington, R. and Gater, R. 2000: Developing child mental health services in developing countries. Journal of Child Psychology and Psychiatry 41, 539-46.

Rushton, J., Bruckman, D. and Kelleher, K. 2002: Primary care referral of children with psychosocial problems. Archives of Pediatrics \& Adolescent Medicine 156, 592-98.

Sayal, K. and Taylor, E. 2004: Detection of child mental health disorders by general practitioners. The British Journal of General Practice 54, 348-52.

Sayal, K., Taylor, E., Beecham, J. and Byrne, P. 2002: Pathways to care in children at risk of attention-deficit hyperactivity disorder. The British Journal of Psychiatry 181, 43-48. 
Sayal, K., Tischler, V., Coope, C., Robotham, S., Ashworth, M., Day, C., Tylee, A. and Simonoff, E. 2010: Parental helpseeking in primary care for child and adolescent mental health concerns: qualitative study. The British Journal of Psychiatry 197, 476-81.

Scott, S., Spender, Q., Doolan, M., Jacobs, B., Aspland, H. and Webster-Stratton, C. 2001: "Multicentre controlled trial of parenting groups for childhood antisocial behaviour in clinical practice". The British Medical Journal 323, 194-98.

Shatkin, J., Belfer, M. and Myron, L. 2004: The global absence of child and adolescent mental health policy. Child and Adolescent Mental Health 9, 104-08.

U.S. Public Health Service. 2000: Report of the Surgeon General's Conference on Children's Mental Health: a national action agenda. Washington, DC: Department of Health and Human Services.

Veit, F.C., Sanci, L.A., Young, D.Y.L. and Bowes, G. 1995: Adolescent health care: perspectives of Victorian general practitioners. The Medical Journal of Australia $163,16-18$.

Webster-Stratton, C., Hollinsworth, T. and Kolpacoff, M. 1989: The long-term effectiveness and clinical significance of three cost-effective training programs for families with conduct-problem children. Journal of Consulting and Clinical Psychology 57, 550-53.

WHO Regional Office for Europe's Health Evidence Network. 2004: What is the evidence of capacity building of primary health care professionals in the detection, management and outcome of depression?. Europe: WHO.

World Health Organization. 2005: Mental health: facing the challenges, building solutions. Denmark: WHO.

Wren, F.J., Scholle, S.H., Heo, J. and Comer, D.M. 2005: How do primary care clinicians manage childhood mood and anxiety syndromes? International Journal of Psychiatry in Medicine 35, 1-12. 